\title{
Mutual Relations of Identity and Foreign Language Learning: An Overview of Linguistic and Sociolinguistic Approaches to Identity
}

\author{
Mohammad Khatib \\ Allameh Tabataba'i University, Iran \\ Email: Mkhatib27@yahoo.com \\ Mohammad Reza Ghamari (corresponding author) \\ Allameh Tabataba'i University, Iran \\ Email: dr_m_rezaghamary2@yahoo.com
}

\begin{abstract}
How language shapes and is shaped by identity is a key topic within sociolinguistics (Riley, 2007). An individual's identity is constituted through a variety of different factors, including the social, territorial, linguistic, cultural, political, religious and ethnic contexts. It helps us know who we are and how social identities are negotiated. The traditional views of the sociology of knowledge and ethnolinguistics on the role of being socially 'other' largely neglect the role of language on one hand. On the other hand, although the expression of self and emotions has been considered one of the principal functions of language, it has largely been neglected by linguists. This study, bridging this gap in mind, examines the effect of identity as a self image in language and on the contrary, the effect of language in identity formation. Also, attempt is made to gain insight into the study of linguistic approaches to identity as far as foreign language learning (FLL) is concerned. Mutual and dynamic relation between identity and language learning and more specifically foreign language learning was realized.
\end{abstract}

Index Terms — identity, language learning, ethnolinguistics, foreign language, self, ethnicity

\section{INTRODUCTION}

The relationship between identity and language learning is of interest to scholars in the fields of second language acquisition (SLA), language education, sociolinguistics, applied linguistics with greater focus on sociological and cultural dimensions of language learning.

In spite of the fact that some scholars such as Deckert and Vickers (2011) claim that the ideas of identity and self are not synonymous, Owens (2003) maintains that they are related. McCool (2009) referring to identity points out, 'everyone is faced with developing a sense of self, a process that begins in adolescence' (p. 6). Joseph (2004), not mentioning the argument, claims that although the expression of self and the emotions is one of the principal functions of language, it has largely been neglected by linguists as being a matter of aesthetic, falling within the field of literary criticism and the rhetoric of persuasion (quoted in Riley, 2007). This perspective, inherited from Aristotelian dualism but still massively present in contemporary code-centred linguistics, saw the emotions as related to the body rather than to the mind and, therefore, as not being amenable to or worthy of scientific investigation. Unquestionably, identity is not a static quality of an individual, but it is a flexible, fluid, and multi-aspected co-construction that is only partially representative of an individual's sense of self. Disregarding the probable differentiation between expression of self and identity, in this paper attempt is made to examine the relation between language learning and identity through analyzing the effects each poses on the other.

\section{REVIEW OF THE RELATED LITERATURE}

The literature on identity is already enormous and seems to be increasing exponentially. It has recently drawn the attention of many linguists. Joseph (2004) argues that identity studies have always privileged the subjective dimension, the self, whereas if we wish to study language as a social phenomenon, we need to redress the balance by paying at least as much attention to the ways in which identities are ascribed and constructed by others on the basis of the culture specific repertoire available. So the study of identity as defined 'self image' is not separate from ethnolinguistics. The main areas of ethnolinguistics include the relationship between language and culture, communicative practices, and cognitive models of language and thought. The ethnolinguist tries to describe and understand the role of language in shaping the ways in which members of a group relate to the world, to one another and to others. These ways of knowing and being are the stuff which identities are made of. Identities consist of meanings, and specific configurations of meanings can be implemented functionally as roles through the community's communicative practices (Riley, 2007). 
Leading scholars from all over the world investigate the role languages have played and now play in the formation of the national and social identity in countries throughout South, East, and Southeast Asia (Simpson, 2007). They consider the relation of the regions' languages to national, ethnic, and cultural identity, and examine the status of and interactions between majority, official, and minority languages.

Also, there is a developing literature on language and social identity and its relation to SLA in which applied and sociolinguistics meet. Roberts (2001) points out that within this literature, the learner is understood as a person with multiple identities, many of them contradictory. Wigglesworth (2005) argues that over the last few decades there has been much debate about the relationship between language and identity and there is some consensus that language is a marker of ethnic identity. Researchers who support this hypothesis also argue that speakers who have strong group identification are likely to consider language to be an important symbol of identity, and this identification may translate into greater use of the language itself. Thus, language identity has often been viewed as an important gauge of language vitality in any given community (Giles and Johnson, 1987).

Peirce (1989, in Candlin and Mercer, 2001) discusses the personal and social investments in learning English as a second language among adult ethnic minority women, how these are observable in their interactions and the ways in which certain social identities are foregrounded or backgrounded. He adds that once notions of social identity are called up, the dominant tradition of SLA as an asocial phenomenon is put into question.

Demont-Heirich (2007) has done a study titled 'language and National Identity in the Era of Globalization: The case of English in Switzerland', in which he examined the rise of English in a multilingual society.

In another study, Pavlenko (2003) focuses on the relationship between national identities and foreign-language education policies and practices. It is argued that shifts in national identity images and sociopolitical allegiances have implications for foreign-language education policies and practices. It would be of interest to see the relationship, if any, between national identity and learning a foreign language, something which appears to be relevant but beyond the focus of this study.

Considering the growth of international relations of our society with other nations and the extended interest in today's growing technology and science throughout the world, learning English as an international language has found a greater importance compared to previous years. Increase in the number of language institutes and their students as well as parents' increasing desire for their children to learn English have provided opportunities for learning a foreign language.

\section{RESEARCH QUESTIONS}

Three major questions are addressed in this study.

1. How does language affect identity?

2. How does identity affect language?

3. How can foreign language learners make use of such a relation?

\section{A. Language from the Viewpoint of Sociolinguistics and Ethnolinguistics}

The "linguistics" in sociolinguistics indicates that we are really focusing on how language is used. The "socio" in Sociolinguistics indicates that we are really focusing on how language is used in social contexts-at how it is used when people interact with one another on interpersonal levels and in larger group, cultural, national, and international levels. So, we begin with the recognition that the language that each of us uses can be different in different situations and with different people. The fact that we humans are complex social creatures means that studying anything we do with language will also be complex. Deckert \& Wickers (2011) argue that it is this complexity in relation to everyday life that makes studying sociolinguistics both fascinating and personal.

In a more narrow definition of the term it is possible to discuss how the use of a particular variety of English, for example, can indicate the area that an individual comes from. The language that people choose to use can be an expression of where they stand. Ellis (2008) defines ethnic identity as "the relationship between the individual and members of the race to which the learner belongs"(p. 336). Language is one of the many systems of signs that humans use to communicate with one another, and since language is systematic, we can ask systematic questions about the different choices that we make when we talk with one another. So, we can ask questions, as posed by William Labov (1966) about whether sales people in different types of New York department stores talked in the same way. They didn't. Then using sociolinguistics, we can talk about the systems of social stratification that affect the worker's choices. The attitude of U.S. movies are portrayed when they show people with southern accents in rather negative ways, or why it is that school systems argue about what variety of English their students should be allowed to use, or even why it is a requirement in many universities around the world that students pass English Proficiency exams (Deckert \& Wickers, 2011). People with various aims in mind employ language.

Shohamy (2006) points out that languages should not be the only criterion that defines societies; rather they should be observed in more integrated ways. Using language as the sole indicator of identity can be considered a discriminatory act. Yule (1985, see also Chastain, 1988) points out that language contains many variations in addition to regional difference. Social variations related to socioeconomic class, education, occupation, age, sex, religion, though not discussed enough, play equally important roles in determining one's speech. 
A person's mind is in a sense the centre of his identity, so if a person thinks in French in order to speak French, one might say that he has, in a way, almost taken on a French identity (see for example Brown, 1994, and Littlewood, 1982). That is the power and the essence of a language. Language is culture. Language is the soul of the country and people who speak it (Tang, 2011).

\section{B. Identity from the Viewpoint of Traditional Linguistics and Sociolinguistics}

The early traditions of sociolinguistics did not specifically refer to the notion of identity. The notion of identity appeared in terms such as self, image of self, social status etc. These works argued that language varied not only by region and dialect, but also by social categories such as class and gender (Labov, 1972; Trudgill, 1972). Deckert \& Wickers (2011) believe that even in the early works, we can see notions that relate to identity and to the idea that identity is connected to language use. Certainly, work on social status addresses notions of identity. In using the language of a particular class, as the sales clerks did in Labov's department store study, the clerks were constructing particular aspects of their identities. Similarly, in using language that reflects a particular gender, even the way they appear in society, individuals are constructing particular aspects of identities. Therefore, in line with Deckert \& Wickers (2011) we can say that the field of sociolinguistics has always addressed issues related to notions of identity.

Linguists analyze and define the world in linguistic terms, often not realizing that languages represent only one aspect of identity. Regarding issues of accent and correctness, language is only one factor in terms of identity but cannot be viewed as the only one; religion, culture, history, gender and additional variables play important roles as well (Shohamy, 2006).

\section{Contemporary Theory and Future Trends}

While much research on language learning in the 1970s and 1980s was directed toward investigating the personalities, learning styles, attitudes and motivations of individual learners, contemporary researchers of identity are mainly concerned with the diverse social, historical, and cultural contexts in which language learning takes place, and how learners negotiate and sometimes resist the diverse positions those contexts offer them.

A number of studies have found statistically significant relationships between measures of subjective ethnolinguistic vitality and educational achievement. Ellinger (2000), for example, found that measures of subjective ethnolinguistic vitality were significant predictors of reading comprehension scores and final examination results in a group of Russian learners of English. Interestingly, the measures of ethnolinguistic identity proved much stronger predictors than other less social measures (for example, self-confidence and emotional distance).

More recent researches have adopted a post-structural approach to the relationship between identity and L2 learning. Riley (2007) believes "the expression of identity should be added to the two traditional major functions of language, representation and communication" (p.12), and Pavlenko (2002) dismissed the assumption that the way people behave is determined by their membership of certain groups as a 'correlational fallacy'. Instead, language is seen as both constituted by and constituting social context, including ethnic membership - it serves as a 'site of identity construction' (Pavelenko, 2002, p. 285, quoted in Ellis, 2008). A good example of how this operates in the case of ethnic identity can be found in Caldas and Caron-Caldas' (2002) study. Their bilingual children had access to both an English and a French ethnic identity; which identity they drew on depended on the social context in which they found themselves. The study suggests that ethnic identity cannot be easily separated from other types of identity. It is for this reason that poststructuralist accounts present identity not as something unitary and stable but rather as multiple and dynamic. Fought (2006) in line with the above-mentioned idea, holds that ethnicity does not occur in isolation from other elements of identity such as class and gender.

Social factors are interwoven and as Ellis (2008, p. 323) points out," there are obvious dangers in seeking to isolate the effects of individual social factors such as age, gender, social class, and ethnic identity." Learners have agency and are likely to try to shape the social context in which they learn rather than passively let it position them. That's why teenagers who have grown up with a minority language can easily mark their independence from their parents and their rejection of parental values by choosing not to speak the minority language (Andersson and Andersson, 1999).

Norton (2000) argued that in many language classrooms, the targeted community may be, to some extent, a reconstruction of past communities and historically constituted relationships, but also a community of the imagination, a desired community that offers possibilities for an enhanced range of identity options in the future.

Issues of identity and language learning will remain at the forefront of research on language education, applied linguistics, and SLA in the future. These issues are seen to be relevant not only to language learners, but to language teachers, teacher educators, and researchers. There is an increasing interest in the ways in which advances in technology have impacted both language learner and teacher identity, and the ways in which the forces of globalization are implicated in identity construction.

\section{The Focus of Social Identity Theory}

Norton (1997) defined 'social identity' as "the relationship between the individual and the larger social world, as mediated through institutions such as families, schools, workplaces, social services, and law courts"( p. 420). Norton's theory of social identity is concerned with the relationship between power, identity, and language learning. As Ellis (2008) maintains, it draws on a number of sources like West (1992). West saw identity as related to desire (for example, 
the desire for recognition, affiliation, security, and safety). So, 'who am I' has to be understood in terms of 'what can I do'. Bourdieu (1991) focused on the relationship between identity and symbolic power. A person's identity has to be understood in terms of the wider, often unequal relationships, in which they participate. Weedon (1997) emphasized the agency of the individual. She proposed a 'theory of subjectivity'. The individual is seen as both the subject of and subject to the relations of power within different social sites. In other words, as Ellis (2008) points out, the individual is the product of social forces but is also able to shape his/her own identity. So, identity can be assumed as the potential ability and it is the social context that provides the language learner with opportunities to enhance this potentiality. Underlying all of these perspectives is the view that language learning is inextricably connected with social conditions, in particular power relations, and it can only be promoted if these are addressed.

Three general questions addressed by the Norton's theory include: (1) how can we facilitate interaction between language learners and target-language speakers? (2) under what conditions do language learners speak? (3) how can we encourage learners to become more communicatively competent? To answer these questions some central propositions are taken into account.

1. Language learning occurs in a context in which we assume at least one addressee.

2. Social identity is multiple, contradictory, and dynamic depending on circumstances.

3. Investment in language learning has much to do with social identity.

4. Identity construction has to be understood in relation to larger social processes and an awareness of the right to speak has to be developed.

Reports of some case studies confirm the relation between identity and language learning claiming language learners either withdraw from contact with native speakers or they could fight to establish a preferred social identity that would afford them opportunities to learn. Different learners prioritize different language skills or combinations of skills depending on how they defined their social identity.

Norton's theory provides a non-deterministic account of how social factors influence L2 acquisition. It explains why some learners are successful and others less so in a more convincing way than any of the preceding theories. It has its own limitations too. It deals mostly with learners in a L2 learning context rather than a foreign language context. Although Ellis (ibid., p. 338) criticizes researchers of the field and points out that Norton is uncritically equating some 'learning opportunities' with 'learning', he does not reject the relationship between the identity language learners assume and their success in language learning even in a foreign language learning context.

Kramsch (1998) argues that it is widely believed that there is a natural connection between the language spoken by members of a social group and that group's identity. By their accent, their vocabulary, their discourse patterns, speakers identify themselves and are identified as members of this or that speech and discourse community. From this membership, they draw personal strength and pride, as well as a sense of social importance and historical continuity from using the same language as the group they belong to.

\section{E. The Effect of Identity in FLL}

There are many ways in which specific social factors affect L2 learning. Ellis (2008) argues that with regard to age, it has been found that younger learners are generally more successful than older learners, possibly because their identity is less threatened by target-language norms. He maintains that the effects of social class may also depend crucially on the setting; in language classrooms that emphasize formal language learning, working-class children are often less successful than middle- class children, whereas there is some evidence to suggest that in immersion settings they do just as well. The central factor, and the one that has attracted the most attention, is ethnic identity. Learners with positive attitudes towards their own ethnic identity and towards the target culture can be expected to develop a strong motivation and high levels of L2 proficiency, while also maintaining their own L1. In a socio-structural model, attitudes based on learners' sense of ethnic identity influence learning through the interactions in which learners participate (Ellis, 2008). A post-structural model does not clearly distinguish between ethnic identity and other forms of identity. It views identity as multiple and dynamic; identity and language learning are interrelated, each influencing the other.

Based on a study of Chinese students learning English, a report from TeacherKevin (2007) states that a student's first language and cultural background can be seen to influence the student's second language acquisition. In China learning English is considered a valuable skill and is not considered to be threatening to the dominant identity of Chinese people in general. Thus, there is general motivation to learn the language, at the same time the students' background in rote learning comes through as a preferred way to learn the current language. Some students have even continued to use such a method of study, even when their teachers suggested against it. These students' first language and cultural experiences are thus heavily influencing how the students go about obtaining their second language skills.

The identity of a person in their second language will be different from than their identity in their own language for a number of reasons. One of the most simple of reasons, especially for students of language, will be based on the student's lack of ability to communicate at the same level as in their first language. Such a situation will effect how the students view themselves as a speaker of the other language, and in the classroom this could even lead to the students avoiding using the second language due to a willingness to save face. In China this could especially be so, as Asian cultures are seen to be "high face" (Mangubhai, 1997) cultures, indeed in some of the classes at this university some of the weaker students have a tendency to sit at the back of the class and try to avoid taking part in activities. When asked to participate, the students will often simply state that they do not know. The reasons for a unwillingness to participate 
however could also be due to inability to do so, but also due to the saving of face by not trying, and thus avoiding a chance to fail.

Other students however also have a positive view of themselves based on their ability to use the second language proficiently, this gives the students an ability to communicate freely in the classroom, gaining the teachers praise, it also allows the students' views and opinions to be expressed clearly, and due to the ability and wiliness to communicate, the student provides for her or himself more opportunity to learn and practice the language, continuing the process of language improvement. From the above example, it might be realized that the students' language ability will also create for the student an identity of a 'good' or 'bad' speaker of English. This formation of identity could then lead the student to reinforce this perceived identity as actual reality through behaviour that will either lead to the students' English improving or weakening. However if a student who perceived themselves as "bad" was to be encouraged to change their own view of themselves then it should be possible for the student to start improvement. Barrnet (2006) mentions how "imagined communities can help students to invest more in the learning" (p. 4).

The different conditions under which language learners speak, read, or write the second language are influenced by relations of power in different sites; learners who may be marginalized in one site may be highly valued in another. For this reason, every time language learners interact in the second language, whether in the oral or written mode, they involve identity construction. However, structural to speak from one identity position may be able to reframe their relationship with their interlocutors and claim conditions and social contexts are not entirely determined. Through human agency, language learners who struggle alternative, more powerful identities from which to speak, thereby enhancing language learning. Norton (2000) also develops the construct of "investment" to better understand the relationship between language learners and the target language.

Accent as a part of one's identity appear as an evidence of the effect of identity in language learning. Having a foreign accent probably means there is a love/hate relationship with it. If you love a certain accent, you find it easier to learn compared to the time when there is hatred toward the accent.

To mention subsequent studies, Ellis (2008) provides another evidence of the effect of identity in language. He maintains that the identities of the participants (i.e. student and teacher) result in the standard speech exchange system. McCool (2009) maintains that values and beliefs relate to different writing strategies. Some cultures use writer responsibility, which places the burden of communication on the writer. Other cultures use reader responsibility, which places the burden of communication on the reader. In reality cultures use a combination of both strategies. Writer responsibility is normally associated with personal identity, while the latter involves group identity.

\section{F. The Effect of FLL in Identity Construction}

According to Warschauer (2007), language has always played an important role in the formation and expression of identity. Language is among the identity layers and social identity can be constructed based on those identity layers. (Karkonan Nasrabadi (2006); see also Ghamari, 2007). Both the identity of the learner, as Mitchell and Myles (2004) believe, and his or her language knowledge, are collaboratively constructed and reconstructed in the course of interaction.

One issue that is prominent in Latino communities for example, and in bilingual immigrant communities generally, is the differences among generations in terms of language use. Interestingly, in these communities we may find that different generations are actually constructing different identities and in a sense ethnicities. Fought (2006) holds that the immigrant generation may see their ethnicity as straightforwardly "Mexican", for example, while the second generation speakers see their eyhnicity as a combination of their Mexican descent and the US culture of the country in which they were born, different from and even in conflict with the ethnicity of their parents. Often, code-switching may be taken as the linguistic symbol of this complex identity.

Another interesting facet of the intergenerational relationship is language competence. In a family with varying ranges of competence in the second language, depending on their individual experiences, parents and children do not share a language for communication in which they both feel completely at ease.

Identity and language and how they interact with one another as two bases of sub-structures of human being societies are so important that some sociologists believe in the nations as outcome of old identities. These identities are constructed by language, traditions, religion, environmental and geographical factors and especially myths (Castells (1997); see also Ghamari and Hassanzadeh, 2010). Language for men not only is a means of communication, but more than that, it's a key to maintaining one's independence and identity in a group."It is seen as both constituted by and constituting social context, including ethnic membership" (Pavelenko, 2002, p. 285, quoted in Ellis, 2008).

According to Fought (2006) language must provide ways of reflecting and constructing the many facets of our identities, and of course it does. Your accent is part of who you are. Many people across the world find foreign accents quite beautiful. Some actors and actresses are chosen for major film roles just for their accent or ability to portray an accent. Accents sound romantic and exotic to the listener in many situations. If you have a foreign accent, you probably have a love/hate relationship with it. On one hand, the accent is part of who you are and points back to one's country of origin. On the other hand, one's accent can cause one to stand out, and some people have a difficult time understanding people when they speak if their accent is quite heavy. Before you work too hard to remove your accent, consider the fact that it could become a positive part of your identity with a little work (Nutt, 2011). 
Sagsayan (2011) states that the first time she realized that the knowledge of a foreign language has to do with identity formation was when she suddenly discovered that for some reason she felt more comfortable to express feelings in English than in Armenian. More comfortable, because she could construct quite a logical, affective discourse in that foreign language, whereas in native language we would end up with incoherent, heavily emotional discourse that would confuse our interlocutor and us even more.

Going back to the ancient saying: knowledge of a foreign language provides you with a new modus operandi through which to discover yourself. I think the role of the teacher is crucial here, because this discovery, this identity formation, sometimes is quite thorny and asks for considerable effort.

Our identities are not just determined by the place and societies where we were born but by the whole life experience and influences we accumulate during our lives. Identity and linguistic/cultural affiliation is not something fixed and engraved in stone. Identity is constantly being influenced by everything and everyone around us -our relationships, our readings, our thoughts and our use of language. Our views of classrooms will be significantly coloured by the initial experience gained out of this first public institution most of us enter during our lives. Our personal identities as language learners within a group derive much from classrooms (Breen, 2001).

It is worth mentioning that the availability of further educational opportunities is often a major factor to affect our choice of language. As English is used to be preferred because it allows for better chances of educational and career promotion in Iran. Shohamy (2006) points out that for speakers, languages are central to their individual and social identities. Decisions about languages that are imposed on whole populations, whether in schools or in society as a whole, can be viewed as contradicting the essence of individual and social freedom because "languages are part of both private and social identity and group membership are not the possession of nations" (p. 161).

Castells (1997, p. 3) explains the central role of identity:"In a world of global flaws of wealth, power, and images, the search for identity, collective or individual, ascribed or constructed, becomes the fundamental source of social meaning". This is not a new trend, since identity, and particularly religious and ethnic identity, have been at the roots of meaning since the dawn of human society. Yet identity is becoming the main and sometimes the only source of meaning. So, meaning is conveyed by language and identity as the source of meaning affects the choice of language.

Lemke (2002) talks about how a speaker of a second language will undertake a new identity as a member of that community of language speakers. The ability to do so, however, is of course based on the students' knowledge and understanding of what that community is.

\section{CONCLUSION}

The recent studies view identity as multiple and dynamic. Language serves as a 'site of identity construction'. Identity can be assumed as the potential ability and it is the social context that provides the language learner with opportunities to enhance this potentiality. There is a mutual and dynamic relationship between the identity language learners assume and their success in language learning even in a foreign language learning context. Ethnic identity cannot be easily separated from other types of identity. It is for this reason that post-structuralist accounts present identity not as something unitary and stable but rather as multiple and dynamic.

In the new era the forces of globalization are implicated in identity construction and an imagined community assumes an imagined identity, and a learner's investment in the second language can be understood within this context. This study was conducted to provide new insights into the relationship between identity construction and the learning a foreign language. The findings present a picture which establishes that there is a relationship between learning a foreign language and formation of identity. Also, investment in language learning has much to do with social identity. Language learning and identity are interrelated, each influencing the other. If other studies come up with similar results we might conclude that language teachers and FL policy makers can feel more at ease introducing cultural aspects of the target language in their classrooms, materials and textbooks on one hand. On the other hand, language learners' desires may lead them to invest in L2 learning and accordingly provide them with learning opportunities. Enhancement of desires and identities, individual or social, should be of interest to language policy makers and text developers.

In sum, this theoretical overview asserts that language and identity are inextricably intertwined, both affect one another and each produces a response from the other.

\section{REFERENCES}

[1] Andersson, Una Cunningham and Staffan Andersson. (1999). Growing Up with Two Languages. London: Routledge.

[2] Barnett, J. (2006). Learner identity and professional standards for ESL specialists. In TESOL in context-Special edition. Melbourne Australia: Council of TESOL Associations.

[3] Bourdieu, P. (1991). Language and symbolic power (J. B. Thompson, Ed.; G. Raymond \& M. Adamson, Trans.). Cambridge, England: Polity Press. (Original work published in 1982).

[4] Breen, M. (Ed.). (2001). Learner Contributions to Language Learning: New Directions in Research. Harlow: Pearson Education.

[5] Caldas, S. and S. Caron-Caldas. (2002). 'A sociolinguistic analysis of the language preferences of adolescent bilinguals: shifting allegiances and developing identities'. Applied Linguistics 23: 490-514.

[6] Candlin, Christopher N. and Neil Mercer (eds.)(2001). English Language Teaching in Its Social Context. London: Routledge.

[7] Castells, Manuel. (1997). The Power of Identity. Malden, MA: Blackwell. 
[8] Chastain, Kenneth (1988). Developing Second-Language Skills Theory and Practice. New York: Harcourt Brace Jovanovich, Publishers.

[9] Chin, Ng Bee and Gillian Wigglesworth. (2007). Bilingualism. Oxon: Routledge.

[10] Deckert, Sharon K. and Caroline H. Vickers. (2011). An Introduction to Sociolinguistics. London: Continuum International Publishing Group.

[11] Demont-Heinrich, Christof. (2005). Language and National Identity in the Globalization: The Case of English in Switzerland. Journal of Communication Inquiry, Vol. 29, No. 1, 66-84(2005).

[12] Ellinger, B. (2000). The relationship between ethnolinguistic identity and English language achievement for native Russian speakers and native Hebrew speakers in Israel'. Journal of Multilingual and Multicultural Development. 21: 292-307.

[13] Ellis, Rod. (2008). The Study of Second Language Acquisition. $2^{\text {nd }}$ Edition. Oxford: Oxford University Press.

[14] Fought, Carmen. (2006). Language and Ethnicity. Cambridge: Cambridge University Press.

[15] Ghamari, Mohammad Reza. (2007). The Role of Language in National Security. نقش زبان در امنيت ملى. 'Danesh-e-Entezami' Quarterly of Police University. Vol. 8, No.4: 94-107.

[16] Ghamari, M. R. and Mohammad Hassanzadeh. (2010). The Role of Language in National Identity. نقش زبان در هويت ملى 'Zabanpazhuhi' A Biannual Journal of Language Studies of Alzahra University. $2^{\text {nd }}$ year. No.3, autumn2010 \& winter 2011 : 153-172.

[17] Giles, H. and P. Johnson. (1987). Ethnolinguistic identity theory: a social psychological approach to language maintenance. International Journal of the Sociology of language, 68: 69-99.

[18] Joseph, J. E. (2004). Language and Identity: National, Ethnic, Religious. Basingstoke: Palgrave Macmillan.

[19] Karkonan Nasrabadi, Mohammad. (2006). War and Identity. Journal of National Studies. Vol.3. No.2: 40-52.

[20] Kramsch, Claire. (1998). Language and Culture. Oxford: Oxford University Press.

[21] Labov, W. (1966). The social stratification of English in New York City. Washington, D. C.: Center for Applied Linguistics.

[22] Labov, W. (1972). Sociolinguistic Patterns. Philadelphia: University of Pennsylvania Press.

[23] Lemke, J.L. (2002). Language development and identity: multiple timescales in the social ecology of learning. In C.Kramsch (Ed), Language acquisition and language socialization. London: Continuum

[24] Littlewood, William. (1982). Foreign and Second Language Learning. Cambridge: Cambridge University Press.

[25] Mangubhai, F. (1997). Primary socialization and cultural factors in second language learning: wending our way through semicharted territory. Australian review of applied linguistics 12:268-98.

[26] McCool, Matthew. (2009). Writing Around the World. A Guide to Writing across Cultures. London: Continuum International Publishing Group.

[27] Mitchell, R. \& F. Myles. (2004). Second Language Learning Theories. London: Hodder Arnold.

[28] Norton, B. (2000). Identity and language learning: Gender, ethnicity, and educational change. Harlow, England: Longman/Pearson.

[29] Norton, B. (1997). 'Language, Identity, and the Ownership of English'. TESOL Quarterly 31: 409-29.

[30] Nutt, A. (2011). Foreign Accent: Is It Part Of Your Identity? Retrieved on July $4^{\text {th }}, 2011$ from: www.english link.

[31] Owens, T. J. (2003). Self and Identity. In J. D. Delamater (Ed.), Handbook of social psychology. New York: Kluwwer Academic / Plenum Publishers.

[32] Pavelenko, A. (2002). 'Poststructuralist approaches to the study of social factors in second language learning and use' in V. Cook (ed.): Portraits of the L2 User. Clevedon, England: Multilingual Matters.

[33] Pavlenko, Aneta (2003). 'Language of the Enemy': Foreign Language Education and National Identity. International Journal of Bilingual Education and Bilingualism. Vol. 6, No. 5, 313-331.

[34] Peirce, B. N. (1989). 'Toward a pedagogy of possibility in the teaching of English internationally: People's English in South Africa'. TESOL Quarterly, 23(3), 401-420.

[35] Riley, Philip (2007). Language, Culture and Identity. London: Continuum.

[36] Roberts, C. (2001). 'Language acquisition or language socialization in and through discourse? Towards a redefinition of the domain of SLA' in C. Candlin and N. Mercer (eds.): English Language Teaching in its Social Context. London: Routledge.

[37] Sagsayan, Christina. (2011). Foreign language and identity. Retrieved on January $15^{\text {th }}, 2011$ from: www.TeachingEnglish.

[38] Shohamy, Elana. (2006). Language Policy. New York: Routledge.

[39] Simpson, Andrew. (2007). Language and National Identity in Asia. Oxford: Oxford University Press.

[40] Tang, Ramona (2011). The Place of "Culture" in the Foreign Language Classroom: A Reflection. Retrieved on June, $20^{\text {th }}, 2011$ from: www.homestead.com/ramonatang/home.html.

[41] TeacherKevin. (2007). How does learning a language affect the Identity students have about themselves, and how their image of self affects learning a language? Retrieved on August $1^{\text {st }}, 2011$ from www. Bukisa.com.

[42] Trudgill, P. (1972). Sex, covert prestige and linguistic change in the urban British of Norwich. Language in Society. 1 (2), 179 195.

[43] Warschauer, Mark. (2007). Language, Identity, and the Internet. In B. Kolko, L. Nakamura, \& G. Rodman (Eds.), Race in Cyberspace. New York: Routledge.

[44] Weedon, C. (1997). Feminist Practice and Poststructuralist Theory. London: Blackwell.

[45] West, C. (1992). 'A matter of life and death'. October 61:30-3.

[46] Wigglesworth, G. (2005).'Current approaches to researching second language learner processes'. Annual Review of Applied Linguistics 25: 98-111.

[47] Yule, G. (1985). The Study of Language. London: Cambridge University Press. 


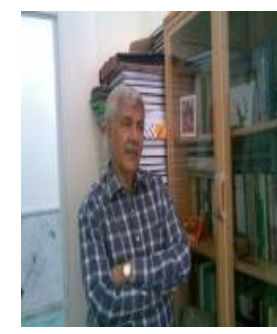

Mohammad Khatib is Assistant Professor of TEFL at Allameh Tabataba'i University. He holds a Ph.D. in TEFL (Allameh Tabataba'i University, 1999), an M.A. and a B.A. in English Literature from Tehran University (1977 and 1972 respectively).

He began teaching at Allameh in 1981 and presently offers graduate and post-graduate courses in SLA Theories, Methodology, Literature in EFL Classes and English Literature.

His main areas of interest include SLA Theories, language learning strategies, culture and the integration of language and literature. He has published some articles on TEFL in Iranian Journals of Applied Linguistics. He has translated a book of short stories from famous writers of the world and published a guidebook on Shakespeare's selected sonnets.

Mohammad Reza Ghamari was born in Toyserkan in 1967. He received a B. A. in English Language and Literature from Shahid Beheshti University in Tehran and an M.A. in TEFL from the Islamic Azad University in Najafabad, in 2006.He is currently a Ph.D. student of TEFL at Allameh Tabataba'I University, and a faculty member of Iranian Police University. As for his professional background, he has taught the English course at various universities. Moreover, he has published some articles and books mainly on TEFL. 